\title{
Cesarean Section without Urethral Catheterization: A Randomized Control Trial
}

\author{
Acharya $\mathrm{S},{ }^{1}$ Uprety DK, ${ }^{2}$ Pokharel $\mathrm{HP},{ }^{2}$ Amatya $\mathrm{R},{ }^{2}$ Rai $\mathrm{R}^{2}$
}

${ }^{1}$ Department of Obstetrics and Gynecology, College of Medical Sciences, Bharatpur

${ }^{2}$ Department of Obstetrics and Gynecology, B. P. Koirala Institute of Health Sciences, Dharan

\section{Corresponding Author}

Sarita Acharya

Department of Obstetrics and Gynecology

College of Medical Sciences

Bharatpur, Nepal.

Email: saritaacharya142@yahoo.com

Citation

Acharya S, Uprety DK, Pokharel HP, Amatya R, Rai R. Cesarean Section without Urethral Catheterization: A Randomized Control Trial. Kathmandu Univ Med J 2012;38(2):18-22.

\begin{abstract}
Background

Urethral catheterization is done as a routine procedure in cesarean section. It is associated with high incidence of urinary tract infections, discomfort, delayed ambulation and longer hospital stay

\section{Objective}

To determine the feasibility and safety of cesarean section without urethral catheterization.
\end{abstract}

\section{Methods}

A prospective, randomized controlled trial was carried out from April 2008 to March 2009, in the Department of Obstetrics and Gynecology, B. P. Koirala Institute of Health Sciences. Among 150 patients who had undergone cesarean section 75 were catheterized and 75 were uncatheterized.

\section{Results}

First void discomfort was significantly associated with the use of indwelling catheter (OR 6.95, Cl $95 \%, 3.74$ to 12.95; $\mathrm{P}<0.001$ ).Significant number of patients with indwelling catheter had signs and symptoms of urinary tract infection (OR $6, \mathrm{Cl} 95 \%, 2.59$ to $13.86 ; \mathrm{P}<0.001)$. Positive urinalysis for urinary tract infection was high in catheterized group $(\mathrm{P}<0.001)$. Hospital stay was shorter in patients without catheter $(p<0.05)$. None of the patients had bladder injury. There were no significant differences in duration of surgery and ambulation time between two groups of patients.

\section{Conclusions}

Cesarean section can be done safely without urethral catheterization with reduced morbidities.

\section{KEY WORDS}

Cesarean section, urethral catheterization, Urinary tract infection

\section{INTRODUCTION}

Cesarean section is the most common major surgical procedure performed in the industrialized world. An increasing number of women are therefore exposed to this procedure.

Traditionally a patient undergoing cesarean section is catheterized with the belief that empty bladder results in better exposure of the lower uterine segment and lowers the risk of bladder injury during surgery. Bruising and edema caused by surgery near the uterovesical area and lower abdominal wall lead to retention of urine that predisposes to urinary tract infection (UTI). ${ }^{1}$ Following delivery of baby, full bladder does not allow proper retraction of uterus leading to uterine atonicity and postpartum hemorrhage
(PPH) and so is a routine practice to keep urethral catheter for 24 hours after surgery. However several studies have shown that cesarean section performed without using urethral catheter also is as safe as the traditional approach. 1-4 Instead, some additional benefits have been reported such as low rate of UTI, less voiding discomfort, early ambulation and shorter hospital stay.

The aim of this study was to determine the feasibility of carrying out cesarean section without catheterization, intraoperative safety, prevalence of UTI, post-operative need of urethral catheterization, prevalence of first voiding discomfort and prevalence of $\mathrm{PPH}$. 


\section{METHODS}

A prospective randomized controlled trial was carried out from April 2008 to March 2009, in the department of Obstetrics and Gynecology, B. P. Koirala Institute of Health Sciences (BPKIHS). A Total of 150 patients who had undergone cesarean section were included in this study, out of which 75 were without urethral catheter and 75 with catheter. Ethical approval for the study was obtained from the ethical committee of BPKIHS. Written informed consent was obtained from all the participants.

Patients with a singleton pregnancy planned for elective as well as emergency cesarean section and who had voided satisfactorily immediately prior to arrival in operation theatre were included in the study. Exclusion criteria were patients with previous cesarean section or prior pelvic surgery, those with clinical features of obstructed labor, with protracted labor for $>800$ min, grandmultipara, polyhydramnios, ante partum hemorrhage, maternal cardiac disease, severe pre-eclampsia and eclampsia, febrile morbidity, receiving morphine related analgesia, with established pre-operative UTI.

Detailed history, physical examination and investigation reports were recorded on a Performa sheet. Pre-operative investigations including urine routine microscopic and urine culture sensitivity was sent.

Patients were randomized by using computer generated random number table. Patients without catheter group were asked to void just before entering the operating room. For catheter group, urinary bladder was catheterized with a $14 \mathrm{~F}$ Foley catheter.

All patients in both groups had received a single dose of intravenous Cefazolin 2 gram after sensitivity test as prophylactic antibiotic just before the commencement of surgery and were operated under spinal anesthesia.

Cesarean section was performed by senior residents by Misgav Ladach technique. ${ }^{5}$ Oxytocin 20 Units was given in a running intravenous drip of ringer lactate solution following the delivery of baby. Intramuscular injection Methergin ${ }^{\circledR}$ $0.2 \mathrm{mg}$ was used when required. The time taken for surgery, $\mathrm{PPH}$, total amount of intravenous fluids used during surgery was recorded. When the urinary bladder was overfilled and was not covered by Doyen's retractor, needle aspiration of bladder was done.

Adequate pain medication was used as necessary. The routine postoperative nursing protocol was followed. Urinary catheter was removed 24 hours after the surgery.

Patients in uncatheterized group were asked to void only upon feeling the urge, rather than according to a time limit. If the urge to void was reported at a time when mobilization was not possible, a bedpan was given. If this failed, helping measures like adequate analgesia and privacy was provided. If the desire to void was reported later, when mobilization was possible, they were helped to a nearby toilet. If still patient had difficulty in passing urine after 6 hours or if abdominal examination shows palpable urinary bladder Foley catheterization was done. ${ }^{6}$ Soakage of vulval pads and presence of fresh bleeding or clots were considered as PPH and catheterization was done.

Time of beginning of ambulation was noted considering the beginning of surgery as the zero time. Discomfort in first voiding was defined as burning, urging, and difficulty at voiding time. The time of first voiding was taken as the interval between start of the operation and first voiding. The operation time was defined as the time from the onset of surgery to the completion of skin closure. The length of hospital stay was defined as the time interval between the onset of surgery and hospital discharge.

Urine routine examination was done on the first postoperative day and urine for culture and sensitivity was sent on the second day. UTI was diagnosed by the presence of clinical features (dysuria, frequency, loin pain, pyrexia) with either the presence of 100 bacteria per milliliter of urine with $\geq 10$ leucocytes per high power field, or $\geq 105$ colony forming unit of pathogenic organism per milliliter of urine on culture. ${ }^{1,2}$

After discharge from the hospital, patients were advised for follow up if symptoms of UTI develops or with the urine culture report.

All statistical calculations were performed using Microsoft Excel version 7 (Microsoft Corporation, NY, USA) and SPSS 11 (SPSS Inc., Chicago, IL, USA) statistical programs. Independent t test was applied for the test of significance of the numerical data. Ordinal data was assessed with the Chi- square and Fischer's exact test as a test of significance. Statistical significance was accepted at $P$ value $<0.05$.

\section{RESULTS}

The populations in uncatheterized and catheterized group were similar in terms of age and period of gestation. The difference in the duration of surgery in the two groups was not significant which indicates that avoidance of catheterization does not affect the ease of surgery (table $1)$. Among the patients without catheter, bladder was retracted with doyen's retractor in 64, however in 11 though bladder was partially retracted and not fully covered by doyen's, operating field was easily visualized. There was no need of needle aspiration of bladder as the operating field was not obliterated. Neither there was any case of bladder injury.

Among the 59 patients who could void on their own, 29 voided after four hours, two of them voided as early as three hours and 12 after six hours (Fig.1).The mean time (mean \pm S.D) taken for first void was $4.64 \pm 0.85$ hours. The first voided volume in most of the cases (54.2\%) was in the range of $100-200 \mathrm{ml}$ and the mean volume (mean \pm S.D) was $180.51 \pm 61.18 \mathrm{ml}$. There was a statistically significant association between the first voiding discomfort and the 
Table.1 Intraoperative and postoperative parameters.

\begin{tabular}{llll} 
Parameters & $\begin{array}{l}\text { Without cath- } \\
\text { eter }\end{array}$ & $\begin{array}{l}\text { With cath- } \\
\text { eter }\end{array}$ & p value \\
$\begin{array}{l}\text { Duration of surgery } \\
\text { (mins.)* }\end{array}$ & $35.24 \pm 7.67$ & $36.99 \pm 6.67$ & 0.139 \\
$\begin{array}{l}\text { Mean ambulation } \\
\text { time(hrs) }\end{array}$ & $14.32 \pm 4.12$ & $15.45 \pm 4.54$ & 0.112 \\
\hline Hospital stay(days)* & $2.9 \pm 0.35$ & $3.06 \pm 0.34$ & 000.3 \\
\hline *Means \pm ST & & & \\
\hline
\end{tabular}

use of indwelling catheter (OR 6.95, Cl $95 \%$, 3.74 to 12.95; $\mathrm{P}<0.001$ ) (Table 2).

Sixteen of the patients in uncatheterized group needed distress catheterization after a mean time interval of 5.16 \pm 1.80 hours. Among them one patient was catheterized in operating room following $\mathrm{PPH}$, two had PPH in the postnatal ward, one had palpable bladder but could not void and 12 of them could not void even after six hours of surgery.

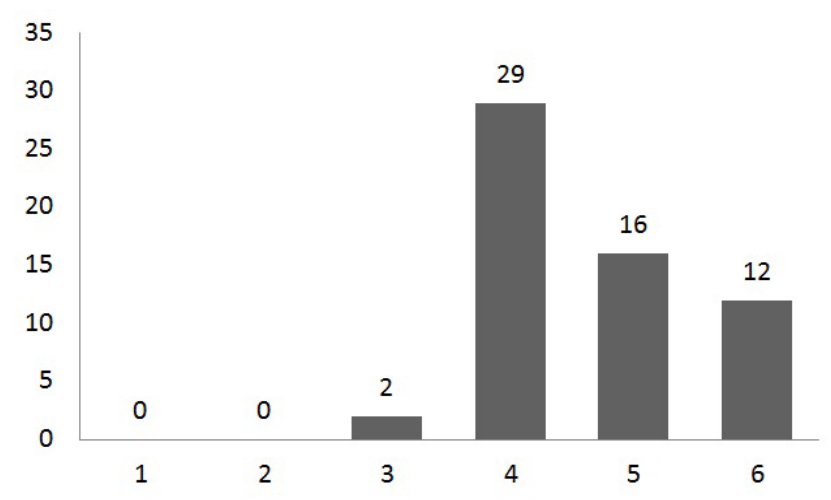

Figure 1. Time of First Void in Cesarean Section without Catheter.

Table.2 Presence of different events in post- operative period.

\begin{tabular}{lllll|}
\hline Parameters & Without catheter & With catheter & p value \\
\hline First void discomfort & 9 & 64 & $<0.001$ \\
\hline Fever & 1 & 11 & 0.03 \\
\hline $\begin{array}{l}\text { Signs and symptoms } \\
\text { of UTI }\end{array}$ & 5 & 40 & $<0.001$ \\
$\begin{array}{l}\text { Urine routine } \\
\text { microscropic }\end{array}$ & 8 & 40 & $<0.001$ \\
$\begin{array}{l}\text { Urine culture and } \\
\text { sensitivity }\end{array}$ & 8 & 44 & $<0.001$ \\
\hline
\end{tabular}

Three of the uncatheterized patients had $\mathrm{PPH}$, first patient in the operating room due to atonic uterus, second patient one hour after surgery and the other after four hours. All were managed conservatively. Fever in the post- operative period in the catheterized patients was mainly contributed by UTI (OR 6.43,Cl 95\%,0.97 to42.29; P= 0.003) (Table 2).Signs and symptoms of UTI, urine routine and microscopic examination and urine culture was significantly associated with the use of urethral catheter (table 2). Escherichia coli were isolated in $12.7 \%$, Acinetobacter anitratus in $10.7 \%$, Enterobacter sps. in $4.7 \%$, Pseudomonas aeruginosa, Staphylococcus aureus and Citrobacter sps. each were in $2 \%$ of the urine culture positive patients. These patients were treated with appropriate antibiotics.
Mean ambulation time was shorter in the patients without urethral catheter though not statistically significant (Table 1).Hospital stay was significantly shorter in patients without catheter than in those with catheter (Table 1).

\section{DISCUSSION}

Maternal morbidity increases dramatically after cesarean section. Principal causes are puerperal infections, hemorrhage and thromboembolism. Among infections UTI is the commonest and is mostly related to urethral catheterization. It accounts for $>80 \%$ of nosocomial UTI and greater postoperative pain. ${ }^{7}$ Bacteriuria develops in at least $10-15 \%$ of the hospitalized patients with an indwelling urinary catheter and the risk of infection is approximately 3-5 \% per day of catheterization. ${ }^{8}$ UTI account for 35- $45 \%$ of all nosocomial infections. ${ }^{9}$ Further the in- patients death among the victims of hospital acquired UTI is 2- 3 times greater than non- bacteriuric patients. ${ }^{9}$ While most of the episodes are asymptomatic or produce minor sequeale due to spread of infections to the contiguous organs, $2-4 \%$ of cases may develop life threatening septicemia. ${ }^{10-12}$

The higher prevalence of UTI in the catheterized patients in our study was similar to study by Senanayeke. ${ }^{2}$ Interestingly, the lower figure was reported by Bartzen et al, whose series also involved avoidance of catheterization. ${ }^{13}$ The increased incidence of UTI associated with cesarean section is probably almost entirely due to catheterization and the best way to prevent it would therefore be to avoid catheterization. ${ }^{14,15}$

Traction on the catheter either inadvertently or by the patient traumatizes the bladder neck, accounting for most episodes of hematuria. Accidental intraurethral distention of the Foley catheter balloon may lead to pressure necrosis and urethral rupture. ${ }^{16}$

The volume of urine produced during cesarean would not produce a significant degree of distension and difficulties or interference during surgery. These results are in agreement with the results obtained by Senanayake, AM Nasr et al and Lang FJ et al. 2,3,17 Even at the end of surgery, the bladder did not distend to a level that would interfere with abdominal wall closure. Further, cesarean section using the Misgav Ladach technique takes a shorter time than other techniques and this would also help to minimize filling of the bladder during surgery. ${ }^{18,19}$

Although the dictum is that the bladder should be catheterized to protect it from intraoperative injury, it could be argued that a slightly filled bladder may be better demarcated and therefore more easily identified intraoperativerely. ${ }^{2}$ In the event of accidental cystotomy, urine would flow out, drawing attention to the damage. This would be a more reliable and earlier indicator of cystotomy than other indirect methods, such as use of an indwelling catheter to detect postoperative hematuria. ${ }^{2}$ In our study there was no case of accidental cystotomy and aspiration 
of the bladder to relieve distension at surgery was not required in any of the cases. So catheterization of bladder would probably have failed to make any difference to the safety of surgery, and might have been an unnecessary intervention.

The mean duration of surgery was not statistically significant between the two groups and was in accordance to the study of Senanayake. ${ }^{2}$

Our study showed first void discomfort in $9 \%$ of uncatheterized and $64 \%$ of catheterized patients, study of Ghoreishi J shows $6 \%$ Vs $93 \% .^{5}$ Nasr AM et al found discomfort at urination at 24 hour and one week after surgery was significantly high in the catheterized group. ${ }^{3}$

The mean time taken for first void was $4.64 \pm 0.85$ hours in our study which was almost similar (5-8 hours in $40.9 \%$ and 8 - 11 hours in $42.5 \%$ ) to the results of J. Goreishi. ${ }^{4}$ It is shorter than the mean time for first void after operation in trial of Senanayake H ( $8.70 \pm 2.37 \mathrm{hrs}$ ) and Nasr AM et al $(7.64 \pm 3.61) .^{2,3}$

Distress catheterization was needed in $21 \%$ of the patients without indwelling catheter which is higher than that in J. Ghoreishi's study (4.4\%). ${ }^{4}$ Six percent of uncatheterized patients required recatheterization in study conducted by Arulkumaran et al. ${ }^{1}$ This higher rate in our study was because the in- out catheterization was not done. Rather directly Foley catheterization was inserted.

Four percent of the patients without indwelling catheter had PPH and this was much lower than the rate of $30 \%$ as given in literature. ${ }^{20}$ All of them responded to conservative measures. In Senanayeke $\mathrm{H}$ results there were $6.68 \%$ cases of postpartum uterine atony causing hemorrhage. ${ }^{2}$ The lower incidence of $\mathrm{PPH}$ in our study may be because multigravida, multiple pregnancy, prolong labour which are the risk factors for PPH were excluded from our study.

Patients in the uncatheterized group ambulated earlier though statistically insignificant in our study. It was 7.7 \pm 3.42 hours in uncatheterized and $13.4 \pm 9.9$ hours in catheterized group in study of Nasr AM et al. ${ }^{3}$ Patients in our set up were reluctant to go to toilet even they were able to ambulate. Rather they preferred to use bed pan. This could explain why less number of patients had difficulty in voiding, despite delayed ambulation.

Patients without catheter were discharged earlier than those with catheter and this was similar to study by Nasr AM et al, 21.8 vs. 45.2 hours. ${ }^{3}$ These results were similar to those demonstrated by Ghoreishi. ${ }^{4}$

There were some limitations of our study. Different surgeons were involved in surgery which could affect the duration of surgery, though it was statistically not significant. We had excluded multigravida and previous cesarean from our study, so the results of our study cannot be generalized.

\section{CONCLUSION}

The routine use of an indwelling catheter for cesarean section is not necessary and with the increasing incidence of this surgery, the benefits of avoiding catheterization are likely to be substantial. Cesarean section can thus be done safely without the routine use of urethral catheter with reduced morbidities.

\section{REFERENCES}

1. Arulkumaran $\mathrm{S}$, Cheng $\mathrm{H}$, Ingermarson I, Low HS, Ratnam SS. Is there a need for routine indwelling catheter after caesarean section? Singapore medical journal 1986; 27: 54-7.

2. Senanayake $H$. Elective cesarean section without urethral catheterization. J Obstet. Gynaecol 2005;31: 32-7.

3. Nasr AM, Elbigawy AF, Abdelamid AE, Al-Khulaidi S, Al-Inany S, Sayed $E H$. Evaluation of the use vs nonuse of urinary catheterization during cesarean delivery: a prospective, multicenter, randomized controlled trial. Journal of Perinatology 2009; 29: 416-21.

4. Ghoreishi J. Indwelling urethral catheter in cesarean delivery. Int $J$ Obstet Gynecol 2003;83: 267-70.

5. Holmgren G, Sjöholm L, Stark M. The Misgav Ladach method for cesarean section: method description. Acta Obstet Gynecol Scand 1999; 78: 615-21.

6. Yip SK, Sahota D, Pang MW, Chang A. Postpartum urinary retention. Acta Obstet Gynecol Scand 2004;83: 881-91.

7. Sedor J, Mulholland SG. Hospital-acquired urinary tract infections associated with the indwelling catheter.Urol Clin North Am 1999;26(4): 821-28.

8. Kasper DL, Braunwald E, Fauci AS, Hauser SL, Longo DL. Harrison's principles of internal medicine. 16th ed. McGraw-Hill Publishers; 2005:1717-18.

9. Kamat SU, Fereirra A, Amonkar D, Motghare DD. Epidemiology of hospital acquired urinary tract infections in a medical college in Goa. Indian J Urol 2009;25: 76- 80.

10. Stamm WE. Urinary tract infections. In: Benett JV, Brachman PS (eds.) Hospital infections. 4th ed. Philadelphia: Lipincott-Raven Publishers; 1998:477- 85.

11. Stamm WE. Catheter associated urinary tract infections: Epidemiology, pathogenesis and prevention. Am J Med 1991;91: 65-71.

12. Turck $M$, Stamm WE. Nosocomial infections of the urinary tract. Am J Med 1981; 70: 651-4.

13. Bartzen PJ, Hafferty FW. Pelvic laparotomy without an indwelling catheter. A retrospective review of 949 cases. Am J Obstet Gynecol 1987;156: 1426-32.

14. Schwartz MA, Wang CC, Eckert LO, Crichlow CW. Risk factors for urinary tract infection in the postpartum period. Am J Obstet Gynaecol 1999;181( 3): 547-53.

15. Symonds EM. The role of trauma and catheterization in puerperal urinary tract infection. J Obstet Gynaecol Br Commonw 1967;74: 294-8.

16. Ramakrishnan K, Mold J W. Urinary Catheters: A Review. The Internet Journal of Family Practice 2005;3: 2. 
17. Lang FJ, Bowen JC, Strong P. Use of indwelling catheter at cesarean delivery. Obstetrics \& Gynecology 2001;97: 66.

18. Fatusic Z, Kurjak A, Jasarevic E, Hafner T. The Misgav Ladach method - a step forward in operative technique in obstetrics. $J$ Perinat Med 2003;31: 395-8.
19. Darj E, Nordstrom ML. The Misgav Ladach method for cesarean section compared to the Pfannenstiel method. Acta Obstet Gynecol Scand 1999;78: 37-41.

20. Jansen AJ, van Rhenen DJ, Steegers EA, Duvekot JJ. Postpartum hemorrhage and transfusion of blood and blood components. Obstet Gynecol Surv 2005 Oct; 60(10): 663-71. 